\title{
Distribuição do metal mercúrio em atum (Thunnus albacares) e pescada bicuda (Cynoscion microlepidotus) capturados no litoral do Rio de Janeiro, Brasil
}

\author{
[Distribution of metal mercury in tuna (Thunnus albacares) and weaker fish \\ (Cynoscion microlepidotus) captured in Rio de Janeiro coast, Brazil] \\ R.J. Medeiros ${ }^{1}$, E.T. Mársico $^{2}$, S.C. São Clemente $^{2}$, M.S. Ferreira ${ }^{1}$ \\ ${ }^{1}$ Aluna de pós-graduação - FV-UFF - UFF - Niterói, RJ \\ ${ }^{2}$ Faculdade de Veterinária, Universidade Federal Fluminense - UFF - Niterói, RJ
}

\section{RESUMO}

O presente estudo verificou a cinética mercurial em órgãos, tecido muscular e conteúdo estomacal de duas espécies de peixes marinhos predadores, identificando os locais de maior acumulação desse metal. Para o processo analítico, foi utilizada a técnica de espectrofotometria de absorção atômica por arraste de vapor a frio. A distribuição de $\mathrm{Hg}$ nas porções analisadas apresenta ampla dispersão. Para o atum, a variação foi de 0,004 $\mu \mathrm{g} . \mathrm{g}^{-1}$ no fígado, nas brânquias e baço, e $0,172 \mu \mathrm{g} \cdot \mathrm{g}^{-1}$ no tecido muscular. Para a pescada bicuda, a variação foi entre $0,013 \mu \mathrm{g} \cdot \mathrm{g}^{-1}$ nas brânquias a $0,250 \mu \mathrm{g} \cdot \mathrm{g}^{-1}$ no tecido muscular. Este último demonstrou ser, nas duas espécies, a porção de maior concentração do metal, atum $=0,080 \pm 0,050 \mu \mathrm{g} \cdot \mathrm{g}^{-1}$ e pescada bicuda $=$ $0,187 \pm 0,030 \mu \mathrm{g} \cdot \mathrm{g}^{-1}$. Os locais de menor concentração na pescada foram as brânquias $0,029 \pm 0,031 \mu \mathrm{g} \cdot \mathrm{g}^{-1}$, e no atum os olhos $\left(0,013 \pm 0,008 \mu \mathrm{g} \cdot \mathrm{g}^{-1}\right)$.

Palavras-chave: atum, pescada bicuda, Thunnus albacares, Cynoscion microlepidotus, mercúrio

\begin{abstract}
The mercuric kinetic in organs, muscular tissue, and stomach contents of two species of marine fish predators was evaluated by the identification of the places showing higher accumulation of the metal. For the analytical process, the used technique was cold vapor atomic absorption spectrometry. The results demonstrated that the distribution of $\mathrm{Hg}$ in the analyzed portions presented wiede dispersion. For Thunnus albacares, the variation was of $0.004 \mu \mathrm{g} \cdot \mathrm{g}^{-1}$ in the liver, gills and spleen, and $0.172 \mu \mathrm{g} \cdot \mathrm{g}^{-1}$ in the muscular tissue. For Cynoscion microlepidotus, the variation was between $0.013 \mu \mathrm{g} \cdot \mathrm{g}^{-1}$ in gills and $0.250 \mu \mathrm{g} . \mathrm{g}_{-}{ }^{1}$ in muscular tissue. The latter was the portion of higher concentration of this metal in both species, T. albacares $=0.080 \pm 0.050 \mu g . g^{-1}$ and $\mathrm{C}$. microlepidotus $=0.187 \pm 0.030 \mu \mathrm{g} \cdot \mathrm{g}^{-1}$, while less concentrations were found in the gills $\left(0.029 \pm 0.031 \mu \mathrm{g} \cdot \mathrm{g}^{-1}\right) \mathrm{in}$ C. microlepidotus and in the eyes $\left(0.013 \pm 0.008 \mu g . g^{-1}\right)$ in T. albacares.
\end{abstract}

Keywords: Tuna, Thunnus albacares, Cynoscion microlepidotus, mercury

\section{INTRODUÇÃO}

A poluição aquática por metais pesados tem sido considerada uma das formas mais nocivas da poluição ambiental, pois esses metais não são degradáveis e tendem a se acumular em organismos vivos cujas conseqüências poderão ir, desde a dizimação da biota, até a intoxicação e envenenamento permanente de seres vivos

Recebido em 29 de outubro de 2007

Aceito em 20 de maio de 2008

Endereço para correspondência (corresponding address)

Rua Senador Vergueiro, 116/302 - 22230-0001 - Rio de Janeiro, RJ

E-mail: renatajmedeiros@gmail.com
(Faria, 2003). Um dos contaminantes químicos de maior relevância para a saúde pública, relacionado ao consumo de pescado, é o metal mercúrio (Hg), em função da sua toxicidade, do poder acumulativo, pelas altas taxas de absorção e pequenas taxas de excreção pelo organismo. Outro fator que estimula as pesquisas desse metal em organismos marinhos é que o maior influxo desse elemento para o ser humano se dá a 
partir do consumo de peixes (Micaroni et al., 2000; Ravichandran, 2004; Bisinoti e Jardim, 2004; Marsico et al., 2007). Durante o século passado, aumentou, no mundo, a preocupação com os possíveis riscos à saúde associados à exposição a metais pesados como o $\mathrm{Hg}$. A exposição a esses poluentes ambientais promove graves danos à saúde, tendo seu efeito mais devastador, no caso do mercúrio, no desenvolvimento do sistema nervoso central e sistema fisiológico geral das crianças (Counter e Buchanan, 2004).

A alta toxicidade desse metal decorre das suas várias formas químicas (metálica, iônicas $\mathrm{Hg}^{+} \mathrm{e}$ $\mathrm{Hg}^{2+}$ e compostos orgânicos), da elevada volatilidade e da solubilidade em água e lipídios, o que facilita a transposição através dos alvéolos pulmonares e da barreira hematoencefálica, com fixação e lesão no sistema nervoso. Deve-se considerar, ainda, sua grande reatividade com os grupos sulfidrila $(\mathrm{SH})$, que levam à inibição de várias enzimas, e sua ação auto-imune (Faria, 2003). Vários estudos demonstram a ação nociva dos metais pesados no organismo, porém somente $\mathrm{o}$ mercúrio está relacionado às intoxicações ocasionadas pelo consumo de pescado e de seus derivados. A escassez de informação sobre a cinética desse metal nos peixes dificulta a compreensão de sua distribuição no organismo e a avaliação de potenciais riscos para a saúde humana e dos animais.

O presente estudo teve como objetivo verificar a cinética do mercúrio em órgãos, tecido muscular e conteúdo estomacal de duas espécies de peixes marinhos predadores, o atum albacora (Thunnus albacares - Bonnaterre, 1788) e a pescada bicuda (Cynoscion microlepidotus, Cuvier 1830), e avaliar a existência de possíveis fontes de contaminação mercurial para os animais e para o homem.

\section{MATERIAL E MÉTODOS}

As análises foram realizadas em duas espécies de peixes marinhos predadores, de elevado consumo e importância na indústria da pesca. Foram estudados oito exemplares de atum albacora ( $T$. albacares) e sete de pescada bicuda $(C$. microlepidotus). No atum, foram analisados olhos, brânquias, estômago, intestinos, cecos pilóricos, baço, fígado, rins, tecido muscular (musculatura branca e musculatura vermelha) e conteúdo estomacal; na pescada bicuda, foram analisados os mesmos órgãos e tecidos, com exceção dos olhos, musculatura vermelha e conteúdo estomacal.

Todos os exemplares, adquiridos inteiros no mercado varejista do município de Niterói, foram acondicionados em recipientes isotérmicos, identificados pela espécie, data de coleta e local de captura. Os atuns foram capturados no litoral do Rio de Janeiro na região próxima à plataforma de petróleo da cidade de Campos, e as pescadas bicudas capturadas no litoral da cidade de Cabo Frio. As coletas ocorreram durante o período compreendido entre agosto de 2004 e setembro de 2005.

Inicialmente, os peixes foram pesados em balança de precisão e mensurados com o auxílio de régua, seguindo-se de evisceração para separação dos órgãos, tecido muscular e conteúdo estomacal. Todas as porções foram identificadas, pesadas individualmente $\mathrm{e}$ acondicionadas a $-25^{\circ} \mathrm{C}$. As amostras foram descongeladas, em geladeira comercial comum a $5^{\circ} \mathrm{C}$ over night, e analisadas em duplicata.

Para a determinação da concentração de mercúrio total, foi utilizada a técnica descrita por Deitz et al. (1973), utilizando o analisador Bacharach Coleman, modelo MAS-50 $\mathrm{B}^{1}$, baseado na técnica de espectrofotometria de absorção atômica por arraste de vapor a frio (EAA-VF) com obtenção dos resultados em microgramas de mercúrio por gramas da amostra $\left(\mu \mathrm{g} \cdot \mathrm{g}^{-1}\right)$

Para validar a técnica utilizada na determinação do Hg-total, foi realizado um exercício de intercalibração em conjunto com dois laboratórios pertencentes ao Centro de Tecnologia Mineral (CETEM). Para tal, uma amostra do peixe da espécie Xiphias gladius, espécie predadora predisposta a apresentar altos teores de mercúrio, foi analisada na Universidade Federal Fluminense, e por duas técnicas distintas no CETEM. Uma técnica utilizou um espectrômetro de absorção atômica portátil modelo RA-915+ acoplado a um aparelho de pirólise para sólidos Lumex modelo RP-91C. A outra utilizou a técnica de EAA-VF, com

${ }^{1}$ Bacharach Inc. Pittsburgh. PA, EUA. 
digestão efetuada em mistura de ácido perclórico, ácido nítrico e ácido sulfúrico. O valor obtido para a mesma amostra nos três laboratórios demonstrou segurança nos resultados, visto que não foi evidenciada diferença significativa em $1 \%$ de probabilidade.

O tratamento estatístico dos resultados obtidos constou de uma análise descritiva simples e comparação das médias de concentração de $\mathrm{Hg}$ total obtidos em cada porção estudada por análise de variância e pelo teste não paramétrico de Friedman. Para medir o grau de correlação entre as duas variáveis, utilizou-se o coeficiente de correlação de Pearson. O programa computacional utilizado foi o Bio Stat 2,0 (Ayres et al., 2000).

\section{RESULTADOS E DISCUSSÃO}

$\mathrm{Na}$ Tab. 1 relacionam-se os dados relativos ao peso (base úmida), comprimento e origem do atum. O comprimento dos exemplares variou entre 42,74 e $106,6 \mathrm{~cm}(57,12 \pm 21,46)$, e o peso entre 2,53 e $12,0 \mathrm{~kg}(5,68 \pm 3,15)$.

Tabela 1. Comprimento, peso e distribuição das massas nos órgãos de atum (Thunnus albacares)

\begin{tabular}{lccc}
\hline \multicolumn{1}{c}{ Variáveis } & Mínimo & Máximo & Média $\pm \mathrm{DP}$ \\
\hline Comprimento $(\mathrm{cm})$ & 42,74 & 106,60 & $57,12 \pm 21,46$ \\
\hline Peso total $(\mathrm{kg})$ & 2,53 & 12,0 & $5,68 \pm 3,15$ \\
\hline Fígado $(\mathrm{g})$ & 36,98 & 75,25 & $44,92 \pm 12,71$ \\
Rins $(\mathrm{g})$ & 14,23 & 25,71 & $18,25 \pm 3,69$ \\
Baço $(\mathrm{g})$ & 6,41 & 29,24 & $13,32 \pm 7,95$ \\
Estômago (g) & 42,36 & 142,87 & $74,75 \pm 39,47$ \\
Brânquias $(\mathrm{g})$ & 56,49 & 267,95 & $104,64 \pm 80,76$ \\
Intestinos $(\mathrm{g})$ & 8,39 & 34,35 & $13,76 \pm 8,9$ \\
Olhos $(\mathrm{g})$ & 24,25 & 39,25 & $29,14 \pm 6,4$ \\
Ceco $(\mathrm{g})$ & 43,69 & 124,32 & $61,75 \pm 27,91$ \\
Conteúdo estomacal $(\mathrm{g})$ & 11,88 & 125,45 & $49,85 \pm 37,69$ \\
\hline
\end{tabular}

DP: desvio-padrão.

Os resultados demonstram que a distribuição do $\mathrm{Hg}$ no atum não é uniforme e apresenta ampla dispersão, com variação entre $0,004 \mu \mathrm{g} \cdot \mathrm{g}^{-1}$ no fígado, nas brânquias e no baço, e $0,172 \mu \mathrm{g} . \mathrm{g}^{-1}$ no tecido muscular. No tecido muscular, foram observados maior teor médio e maior valor individual. Os valores mínimo, máximo seguidos de média e desvio-padrão obtidos para cada órgão ou tecido analisado podem ser observados na Tab. 2.

Tabela 2. Concentração individual de $\mathrm{Hg}$ total $\left(\mu \mathrm{g} \cdot \mathrm{g}^{-1}\right)$ em órgãos, tecido muscular e conteúdo estomacal de atum (Thunnus albacares)

\begin{tabular}{lccc}
\hline \multicolumn{1}{c}{ Localização } & Mínimo & Máximo & Média $\pm \mathrm{DP}$ \\
\hline Fígado & 0,004 & 0,041 & $0,018 \pm 0,012 \mathrm{a}$ \\
Rins & 0,011 & 0,055 & $0,027 \pm 0,018 \mathrm{a}$ \\
Baço & 0,004 & 0,058 & $0,033 \pm 0,020 \mathrm{a}$ \\
Estômago & 0,011 & 0,128 & $0,049 \pm 0,044 \mathrm{a}$ \\
Brânquias & 0,004 & 0,066 & $0,023 \pm 0,020 \mathrm{a}$ \\
Intestinos & 0,005 & 0,055 & $0,023 \pm 0,016 \mathrm{a}$ \\
Olhos & 0,005 & 0,029 & $0,013 \pm 0,008 \mathrm{a}$ \\
Cecos & 0,008 & 0,040 & $0,019 \pm 0,010 \mathrm{a}$ \\
Conteúdo estomacal & 0,006 & 0,085 & $0,021 \pm 0,025 \mathrm{a}$ \\
Musculatura vermelha & 0,029 & 0,156 & $0,059 \pm 0,043 \mathrm{a}$ \\
Musculatura branca & 0,033 & 0,172 & $0,080 \pm 0,050 \mathrm{~b}$ \\
\hline
\end{tabular}

DP: desvio-padrão.

Valores seguidos por letras distintas na coluna diferem entre si $(\mathrm{P}<0,05)$. 
O maior teor médio de $\mathrm{Hg}$ total ocorreu na porção de músculo branco $\left(0,080 \mu \mathrm{g} \cdot \mathrm{g}^{-1}\right)$, seguido pelo músculo vermelho $\left(0,059 \mu \mathrm{g} \cdot \mathrm{g}^{-1}\right)$, e a diferença entre estas porções é significativa $(\mathrm{P}<0,05)$. Considerando-se as amostras estudadas, não foi evidenciada correlação entre o tamanho e o peso dos exemplares com o teor de $\mathrm{Hg}$ total, exceto nas amostras de baço, onde se constatou uma correlação positiva $(\mathrm{r}=0,528)$ significativa ao nível de $5 \%$ de probabilidade.

$\mathrm{Na}$ Tab. 3 relacionam-se os dados relativos ao peso (base úmida), comprimento, origem de cada exemplar e de cada órgão. O comprimento dos exemplares variou entre 52,00 e $56,82 \mathrm{~cm}$ $(54,25 \pm 1,54)$ e, o peso, entre 1,07 e $1,29 \mathrm{~kg}$ $(1,15 \pm 0,07)$.

Tabela 3. Comprimento, peso e distribuição das massas em órgãos de pescada bicuda (Cynoscion microlepidotus)

\begin{tabular}{lccc}
\hline \multicolumn{1}{c}{ Variáveis } & Mínimo & Máximo & Média $\pm \mathrm{DP}$ \\
\hline Comprimento $(\mathrm{cm})$ & 52,00 & 56,82 & $54,25 \pm 1,54$ \\
\hline Peso total $(\mathrm{kg})$ & 1,07 & 1,29 & $1,15 \pm 0,07$ \\
\hline Fígado $(\mathrm{g})$ & 9,25 & 27,07 & $14,57 \pm 5,99$ \\
Rins $(\mathrm{g})$ & 1,22 & 6,15 & $3,95 \pm 1,55$ \\
Baço $(\mathrm{g})$ & 0,55 & 1,41 & $0,97 \pm 0,32$ \\
Estômago $(\mathrm{g})$ & 4,00 & 10,62 & $8,53 \pm 2,35$ \\
Brânquias $(\mathrm{g})$ & 3,79 & 25,25 & $16,36 \pm 6,53$ \\
Intestinos $(\mathrm{g})$ & 1,28 & 4,10 & $3,15 \pm 0,99$ \\
Cecos $(\mathrm{g})$ & 3,31 & 10,65 & $7,66 \pm 2,28$ \\
\hline
\end{tabular}

DP: desvio-padrão.

A distribuição do $\mathrm{Hg}$ total nos órgãos e na porção muscular da pescada bicuda seguiu o mesmo comportamento descrito para os exemplares de atum, com médias, no entanto, bastante superiores. A distribuição também não foi uniforme, apresentando ampla dispersão, com variação entre $0,013 \mu \mathrm{g} \cdot \mathrm{g}^{-1}$, nas brânquias, a $0,250 \mu \mathrm{g} \cdot \mathrm{g}^{-1}$, no tecido muscular.
Os valores mínimo, máximo seguidos de média e desvio-padrão obtidos para cada amostra estudada são apresentados na Tab. 4. Não foi evidenciada correlação entre o tamanho e peso dos exemplares com o teor de $\mathrm{Hg}$ total, em nenhuma estrutura analisada.

Tabela 4. Concentração de $\mathrm{Hg}$ total $\left(\mu \mathrm{g} \cdot \mathrm{g}^{-1}\right)$ em órgãos e tecido muscular de pescada bicuda (Cynoscion microlepidotus)

\begin{tabular}{lccc}
\hline Localização & Mínimo & Máximo & Média $\pm \mathrm{DP} *$ \\
\hline Fígado & 0,020 & 0,145 & $0,081 \pm 0,002$ \\
Rins & 0,014 & 0,180 & $0,120 \pm 0,003$ \\
Baço & 0,047 & 0,200 & $0,118 \pm 0,002$ \\
Estômago & 0,030 & 0,183 & $0,092 \pm 0,003$ \\
Brânquias & 0,013 & 0,080 & $0,029 \pm 0,031$ \\
Intestinos & 0,030 & 0,150 & $0,067 \pm 0,001$ \\
Cecos & 0,036 & 0,200 & $0,110 \pm 0,003$ \\
Tecido muscular & 0,162 & 0,250 & $0,187 \pm 0,030$ \\
\hline
\end{tabular}

*Não diferiram estatisticamente.

Não foi observada diferença significativa entre a concentração de $\mathrm{Hg}$ total no estômago e brânquias das duas espécies. Entre as amostras de fígado, rins, baço, cecos e musculatura branca, foi evidenciada uma diferença estatisticamente significativa $(\mathrm{P}<0,01) \quad$ com teores de $\mathrm{Hg}$ total bem mais elevados na pescada bicuda. Para as amostras de intestino, essa diferença foi significativa $(\mathrm{P}<0,05)$, também com o maior valor para a pescada bicuda. 
Segundo Régine et al. (2006), existem diferenças significativas na bioacumulação de $\mathrm{Hg}$ entre as espécies, em razão, principalmente, dos hábitos alimentares. Esse autores observaram ampla dispersão entre as amostras analisadas, fato caracterizado pelos altos valores do desviopadrão verificados para as estruturas estudadas (músculo, intestinos, estômago, fígado e rins). Esse resultado foi também observado neste estudo e sugere que o $\mathrm{Hg}$ não se distribui uniformemente no organismo dos peixes.

A pescada bicuda (C. microlepidotus) apresentou maiores concentrações de $\mathrm{Hg}$ total em todos os órgãos e tecidos, com o maior valor médio para a porção muscular e menor valor médio para as brânquias. Não foi possível obter valores de comparação, pois não existem dados disponíveis na literatura para essa espécie. Entretanto, podem-se comparar estes resultados com outros estudos efetuados em peixes predadores, como Cynodon gibbus e Hoplias aimara pesquisados por Régine et al. (2006), que observaram os maiores valores na porção muscular, e os menores nas brânquias. Em contraponto aos resultados da pescada bicuda, os valores de $\mathrm{Hg}$ encontrados no fígado das espécies acima citadas foram elevados, superando o teor médio observado na porção muscular.

$\mathrm{O}$ atum ( $T$. albacares) apresentou menores valores médios para as porções analisadas em relação à pescada bicuda. Em outro estudo, com tunídeo (Thunnus thynnus) e espadarte (Xiphias gladius), foram observados valores médios mais elevados na musculatura branca $\left(1,02 \mu \mathrm{g} \cdot \mathrm{g}^{-1} \mathrm{e}\right.$ $0,49 \mu \mathrm{g} \cdot \mathrm{g}^{-1}$, respectivamente) que os valores encontrados no presente estudo para o atum (Storelli e Marcotrigiano, 2001).

Storelli et al. (2005) observaram valores médios para $\mathrm{Hg}$ total no fígado $\left(0,39 \pm 0,10 \mu \mathrm{g} \cdot \mathrm{g}^{-1}\right)$ e no tecido muscular $\left(0,20 \pm 0,007 \mu \mathrm{g} \cdot \mathrm{g}^{-1}\right)$ de $T$. thynnus, superiores aos encontrados neste estudo. Esses autores também analisaram os valores médios de $\mathrm{Hg}$ total no fígado $\left(0,19 \pm 0,09 \mu \mathrm{g} \cdot \mathrm{g}^{-1}\right) \mathrm{e}$ no tecido muscular $\left(0,07 \pm 0,04 \mu \mathrm{g} \cdot \mathrm{g}^{-1}\right)$ de $X$. gladius. Em $X$. gladius, como relatado para $T$. thynnus, o fígado apresentou teor de $\mathrm{Hg}$ total maior que os valores deste estudo. Nas amostras de tecido muscular, os valores apresentaram-se próximos ao observado no tecido muscular de $T$. albacares neste estudo, inclusive com dispersão semelhante $(0,020-0,150$ para $X$. gladius e 0,033-0,172 para T. albacares).

O conteúdo estomacal dos atuns não apresentou concentrações elevadas de $\mathrm{Hg}$ total, embora esse representasse apenas uma refeição diária e o influxo de $\mathrm{Hg}$ por apenas uma via de absorção. É importante lembrar a diversidade alimentar dessa espécie, que pode modificar de acordo com vários fatores, inclusive as estações do ano (Vaske Jr e Castello, 1998; Frodello et al., 2000). Essa diversidade alimentar pode interferir, tanto no teor de $\mathrm{Hg}$ do conteúdo estomacal, como em sua distribuição entre os órgãos e os tecidos do peixe. Os exemplares de pescada bicuda não apresentaram conteúdo estomacal, impossibilitando-lhe a análise.

As altas concentrações de $\mathrm{Hg}$ no tecido muscular das duas espécies estudadas confirmam as observações de McKim et al. (1976); Olson et al. (1978); Yallouz et al. (2001); Berntssen et al. (2004); Marsico et al. (2007) de que a musculatura dos peixes apresenta concentrações elevadas desse metal. Tal fato caracteriza a importância da contínua monitorização, em especial das espécies de importância comercial com elevado consumo.

Valores baixos de $\mathrm{Hg}$ total foram evidenciados nas brânquias das duas espécies estudadas. Segundo Romeo et al. (1999), a concentração de metais pesados nas brânquias reflete a concentração desses metais na água. Olson et al. (1978) descrevem que baixo teor de $\mathrm{Hg}$ nas brânquias é reflexo de dois processos, um relacionado à permeabilidade do epitélio branquial, e o outro às modificações nas ligações do $\mathrm{Hg}$ com o epitélio branquial. Dessa forma, pode-se considerar que o influxo do $\mathrm{Hg}$ em espécies predadoras está mais relacionado com os hábitos alimentares que com o processo de adsorção por meio da via respiratória.

O fígado destaca-se como órgão preferencial de concentração do $\mathrm{Hg}$ devido à presença de metalotioneína, proteína rica em grupamento sulfidrila, com o qual o $\mathrm{Hg}$ possui alta afinidade (Olson et al., 1978; Romeo et al., 1999; Berntssen et al., 2004). Neste estudo, entretanto, não foram observados valores elevados nesse órgão nas duas espécies (Tab. 2 e 4). Ressalta-se a importância de estudos mais abrangentes desse órgão nessas e em outras espécies de peixes. 
Exceto para o baço do atum, que apresentou correlação significativa entre peso e concentração de $\mathrm{Hg}(\mathrm{r}=0,52 ; \mathrm{P}<0,05)$, não houve correlação entre a concentração de $\mathrm{Hg}$ nos órgãos e o peso e o tamanho dos peixes. Sellanes et al. (2002) também não evidenciaram uma correlação entre o tamanho e o teor de $\mathrm{Hg}$ total em amostras de tunídeos (T. thynnus). Souza e Goyannes (1992) igualmente não constataram, em amostras de atuns, correlação entre a concentração de $\mathrm{Hg}$ e o peso.

Monteiro e Lopes (1990), ao analisarem 136 exemplares de meka ( $X$. glandius), observaram uma correlação significativa entre o tamanho e a concentração de $\mathrm{Hg}$ total na musculatura em exemplares com mais de $125 \mathrm{~cm}$ de comprimento. Os autores observaram que as fêmeas atingem esse comprimento, de uma maneira geral, antes dos machos e, portanto, com menos idade. Dessa forma, as fêmeas apresentam menor concentração de $\mathrm{Hg}$ total. Então, a correlação, na realidade, diz respeito à idade dos exemplares estudados, o que pode justificar os baixos resultados obtidos com a espécie $T$. albacares. Johnels et al. (1967), citados por Holden (1973), sugerem que esse fato pode se relacionar com a zona geográfica onde os peixes são capturados. Nos locais onde existe histórico de descarga de rejeitos industriais contendo $\mathrm{Hg}$, existem evidências de correlação linear positiva significativa entre os teores encontrados e a idade ou o peso/tamanho dos peixes e, onde não há histórico de descarga industrial, tal relação é inexistente.

\section{CONCLUSÃO}

Embora os valores obtidos estejam abaixo do limite máximo permitido pela legislação brasileira, é de extrema importância o monitoramento dessas espécies para garantir a qualidade desses e dos subprodutos, visando à qualidade desses alimentos e a saúde pública.

\section{REFERÊNCIAS BIBLIOGRÁFICAS}

AYRES, M.; AYRES JUNIOR, M.; AYRES, D.L. et al. Bio Stat 2.0. Aplicações estatísticas nas áreas das ciências biológicas e médicas. Belém: Sociedade civil Mamirauá/CNPq, 2000.

BERNTSSEN, M.H.G; HYLLAND K.; JULSHAMN, K. et al. Maximum limits of organic and inorganic mercury in fish feed. Aquacult. Nutr., v.10, p.83, 2004.

BISINOTI, M.C.; JARDIM, W.F.O Comportamento do metilmercúrio (MetilHg) no ambiente. Quim. Nova, v.27, p.593-600, 2004.

COUNTER, S.A.; BUCHANAN, L.H. Mercury exposure in children: a review. Toxicol. Appl. Pharmacol., v.198, p.209-230, 2004.

DEITZ F.D.; SELL J.L.; BRISTOL D. Metals and others elements - Rapid, sensive method for determination variety of biological samples. $J$. Assoc. Off. Anal. Chem., v.56, p.378-382, 1973.

FARIA, M.A.M. Mercuralismo metálico crônico ocupacional. Rev. Saúde Pública, v.37, p.116127, 2003.

FRODELLO, J.P.; ROMÉO M.; VIALE D. Distribution of mercury in the organs and tissues of five toothed-whale species of the Mediterranean. Environ. Pollut., v.108, p.447452, 2000.

HOLDEN, A.V. Mercury in fish and shellfish. A review. J. Food Technol., v.8, p.1-25, 1973.

JOHNLES, A.; OLSON, M.; WESTERMARK, T. Kvicksilver I fish undersökningar av kvicksilverhalter I svensk fisk. Var Föda, v.7, p.66-103, 1967.

MÁRSICO, E.T.; MACHADO, M.E.S.; KNOFF, M. et al. Total mercury in sharks along the southern Brazilian Coast. Arq. Bras. Med. Vet. Zootec., v.59, p.1593-1596, 2007.

McKIM, J.M.; OLSON, G.F.; HOLCOMBE, G.W. et al. Long term effects of methylmercury chloride on three generations of brook trout (Salvelinus fontinalis): toxicity, accumulation, distribution, and elimination. J. Fish. Res. Board Can., v.33, p.2726-2739, 1976.

MICARONI, R.; MESQUITA, C.; BUENO, M. et al. Compostos de mercúrio: revisão de métodos de determinação, tratamento e descarte. Quim. Nova, v.23, p.487-495, 2000.

MONTEIRO, L.; LOPES, H. Mercury contents of Swordfish, Xiphias gladius, in relation to legth, weight, age and sex. Mar. Pollut. Bull., v.21, p.293-296, 1990.

OLSON, K.; SQUIBB, K.; COUSINS, R. Tissue uptake, subcellular distribution, and metabolism of ${ }^{14} \mathrm{CH}_{3} \mathrm{HgCl}$ and $\mathrm{CH}_{3}{ }^{203} \mathrm{HgCl}$ by Rainbow 
trout, Salmo gairdneri. J. Fish. Res. Board Can., v.35, p.381-390, 1978.

RAVICHANDRAN, M. Interactions between mercury and dissolved organic matter - A review. Chemosphere, v.55, p.319-331, 2004.

RÉGINE, M.; GILLES, D.; YANNICK, D. et al. Mercury distribution in fish organs and food regimes: Significant relationships from twelve species collected in French Guiana (Amazonian basin). Sci. Total Environ., v.368, p.262-270, 2006.

ROMEO, M.; SIAU, Y.; SIDOUMOU, Z. et al. M. Heavy metal distribution in different fish species from the Mauritania coast. Sci. Total Environ., v.232, p.169-175, 1999.

SELLANES, A.G.; MÁRSICO E.T.; SANTOS, N.N. et al. Mercúrio em peixes marinhos. Acta Sci. Vet., v.30, p.107-112, 2002.

STORELli, M.M.; MARCOTRIGIANO, G.O. Total mercury levels in muscle tissue of swordfish (Xiphias gladius) and bluefin tuna (Thunnus thynnus) from the Mediterranean Sea (Italy). J. Food Prot., v.64, p.1058-1061, 2001.

STORELLI, M.M.; GIACOMINELLISTUFFLER, R.; STORELLI, A. et al. Accumulation of mercury, cadmium, lead and arsenic in swordfish and bluefin tuna from the Mediterranean Sea: A comparative study. Mar. Pollut. Bull., v.50, p.1004-1007, 2005.

SOUZA, J.V.B.; GOYANNES, A.L. Contenido de mercurio en productos de la pesca por espectrometría de absorción atómica en vapor frío. An. Bromatol., v.44, p.45-57, 1992.

VASKE Jr, T. e CASTELLO, J.P. Conteúdo estomacal da Albacora-Laje, Thunnus Albacares durante o inverno e primavera no Sul do Brasil. Rev. Bras. Biol., v.58, p.112-116, 1998.

YAllOUZ, A.; CAMPOS, R.; LOUZADA, A. Níveis de mercúrio em atum sólido enlatado comercializado na cidade do Rio de Janeiro. Cien. Tecnol. Alim., v.21, p.1-4, 2001. 